\title{
Effect of 4-aminopyridine and single-dose methylprednisolone on functional recovery after a chronic spinal cord injury
}

\author{
Siavash S Haghighi ${ }^{1}$, Adam Clapper ${ }^{1}$, Gayle C Johnson ${ }^{2}$, Amy Stevens ${ }^{1}$ and Arisa Prapaisilp ${ }^{1}$ \\ ${ }^{1}$ Division of Neurosurgery, Department of Surgery, University of Nebraska Medical Center, and ${ }^{2}$ Department of \\ Veterinary Pathology, University of Missouri-Columbia, Columbia, Missouri, USA
}

\begin{abstract}
The demyelination process is an important factor contributing to long term sensory and motor impairments after spinal cord injury (SCI). Exposure of axonal $\mathrm{K}^{+}$channels after demyelination may contribute to blockage of action potentials across the injury site. A $\mathrm{K}^{+}$ channel blocker, 4-aminopyridine (4-AP), has been effective in restoring some sensory and motor impairment in incomplete SCI patients. The long-term effect of this compound in chronic model of SCI is not known. In this study, after a compression injury of 50 grams in rats, a randomized treatment was initiated 3 weeks after the initial injury which was followed by daily administration of 4 -AP at $2 \mathrm{mg} / \mathrm{kg}(n=8), 4 \mathrm{mg} / \mathrm{kg}(n=8)$, and $6 \mathrm{mg} / \mathrm{kg}(n=8)$ for 4 weeks. A group of methylprednisolone (MP)-treated $(30 \mathrm{mg} / \mathrm{kg}, n=8)$ and non-treated animals $(n=8)$ were included for comparison. The functional motor outcome was measured in each animal at regular time points up to 4 weeks post-treatment. All animals receiving $6 \mathrm{mg} /$ $\mathrm{kg}$ developed generalized seizure and were excluded from the study. In the other animal groups, analysis of the behavioral outcome and neuro-pathological changes were essentially similar and did not show any significant effect of treatment. Our data indicate that daily administration of 4-AP, over 4 weeks of treatment period, lacks any significant effect on axonal function in chronically injured rats. This could be due to (a) lack of significant numbers of demyelinated axons which could improve the functional outcome and (b) a treatment regimen that was not adequate to contribute to a better functional outcome. One time bolus-administration of MP at $30 \mathrm{mg} / \mathrm{kg}$ also did not ensure a better functional outcome.
\end{abstract}

Keywords: chronic spinal cord injury; 4-aminopyridine; methylprednisolone; rats

\section{Introduction}

In chronic spinal cord injury (SCI), demyelination has been shown to be an important factor contributing to long term sensory and motor impairments. ${ }^{1-4}$ The loss of myelin sheath around myelinated axons promotes the exposure of $\mathrm{K}^{+}$channels in the internodal region, which leads to an excessive $\mathrm{K}^{+}$efflux into the extracellular space and subsequent blockage of nerve action potentials. 5,6 This event is similar to voltage clamping of the cell membrane close to the $\mathrm{K}^{+}$ equilibrium potential $\left(\mathrm{E}_{\mathrm{k}}\right)$, thus opposing depolarization and interfering with nerve conduction in demyelinating axons. ${ }^{7}$ Therefore, voltage-sensitive $\mathrm{K}^{+}$ channel blockers should, at least in theory, facilitate propagation of impulses through demyelinated segments of axons.

Different $\mathrm{K}^{+}$channel blockers have been used in demyelinating diseases such as multiple sclerosis ${ }^{8-11}$ with some clinical improvement. Among these compounds, 4-Aminopyridine (4-AP) has been also effective in restoring some sensory and motor impairment in chronic, but incomplete, spinal cord injuries in clinical trials or experimental animals. ${ }^{1,12-15}$

Correspondence: Siavash S. Haghighi, D.V.M., Ph.D.
Administration of 4-AP at $0.5-1 \mathrm{mg} / \mathrm{kg}$ has produced immediate amelioration of deficits in canine paraplegia. This functional recovery occurred within $15-$ 45 min of the drug administration but it fully reversed within a few hours. ${ }^{15}$

The initial clinical trial for application of 4-AP in patients with SCI was an open, unblinded study using $2 \mathrm{mg}$ every $20 \mathrm{~min}$ up to $24 \mathrm{mg}$ of the compound. ${ }^{1}$ This treatment did not benefit patients with complete SCI. In complete injuries, there was evidence of enhanced neurologic function, however, this improvement was not functionally important. In a more recent clinical trial, 4-AP was given to eight patients in a randomized, double-blind, crossover fashion. ${ }^{12}$ 4-AP was associated with significant but transient neurological improvement in five of six patients. In this study, because the effect of 4-AP persisted over $48 \mathrm{~h}$ after termination of the drug infusion, authors speculated that there were other therapeutic mechanisms than the primary effect of 4 -AP on $\mathrm{K}^{+}$channels.

In experimental trials, the levels of neurological recovery was limited by 4 -AP dosage. ${ }^{16}$ In dogs, 4-AP administration has produced adverse reactions such as anxiety, nervousness and seizures. ${ }^{15}$ 
The objective of the present study was to determine if a long term (4 weeks) administration of the 4-AP would improve functional recovery in chronic model of SCI in rats. An additional group of animals treated with single dose of methylprednisolone was included in the study for comparison with a more traditional therapy.

\section{Materials and methods}

\section{Surgical procedures and post operative care}

Forty male rats (Harlan Sprague-Dawley Inc., Indianapolis, IN) weighing $473 \pm 51 \mathrm{gm}$ were used. Animals were housed individually and maintained in a $12 \mathrm{~h} \mathrm{light/dark}$ cycle. Halothane anesthesia was induced at $4 \%$ after placing the animals in a plastic chamber. The anesthetized animals were transferred and fixed to a steriotactic frame (Model 1404, David Kopf Instruments, Tujunga, California) and were placed in a prone position on a heating blanket (Aquamatic K-model and K-pad, Gorman Rupp Industries, Belleville, Ohio). Body temperature was maintained between $36.5^{\circ} \mathrm{C}$ and $37.5^{\circ} \mathrm{C}$ (Model 401, rectal thermomenter, Yellow Springs Instruments Co, Yellow Springs, Ohio). Halothane anesthesia was continued by mask. The EKG was continuously monitored using a physiograph.

Under sterile conditions, a midline incision at the lower thoracic level was performed. Under microscope, a T10-T11 dorsal laminectomy was performed. An aluminum compression device (weighing $5 \mathrm{~g}$ ) with a rectangular concave contact surface $(4 \times 4 \mathrm{~mm})$ and a round platform was positioned on the dorsal midline of the spinal cord using a micropositioner. ${ }^{17}$ The compressive injury was produced by placing a $45 \mathrm{~g}$ weight on the platform (total compression weight $=50 \mathrm{~g}$ ) for $90 \mathrm{~s}$.

After the injury, the wounds were closed in layers and the animals were placed into cages. Animals received ampicillin $50 \mathrm{mg} / \mathrm{kg}$ IM before and every $6 \mathrm{~h}$ after the surgery up to $24 \mathrm{~h}$. Buprenorphine $0.01 \mathrm{mg} /$ $\mathrm{kg}$ SQ was also administered to relieve postoperative pain. The urinary bladder was expressed in each animal four times a day until full recovery of spontaneous micturition occurred.

\section{Drug administration}

Rats were randomly placed into five groups. Group\#1 $(n=8)$ received an intraperitoneal bolus dose of methylprednisolone $(30 \mathrm{mg} / \mathrm{kg})$ immediately after the injury. Groups \# 2, 3, 4 received daily I.P. injections of $4-\mathrm{AP}$ at $2 \mathrm{mg} / \mathrm{kg}(n=8), 4 \mathrm{mg} / \mathrm{kg}(n=8)$, and $6 \mathrm{mg} / \mathrm{kg}$ $(n=8)$ starting at the 3 rd weeks post-injury through the 7 th weeks. Animals receiving $6 \mathrm{mg} / \mathrm{kg}$ 4-AP developed generalized seizure immediately after the first dosage administration. Treatment was terminated, and this group was excluded from the study. Control group $(n=8)$ received an equal volume of bacteriostatic saline post-injury.

\section{Behavioral assessment}

All animals were closely monitored for 7 weeks after the initial injury. During this period, each animal was subjected to a behavior examination using the included plane (IP), toe spreading reflex (TSR) and a modified Tarlov's scale (TS). The IP task measures the animal's ability to maintain its body position when placed on an inclined board. ${ }^{18}$ The TSR is elicited after picking the animal and allowing the hindlimbs to hang free. ${ }^{19}$ The TS indicates the animal's hindlimb locomotor ability. ${ }^{20}$ Each animal was tested prior to the injury (Day 0) and at days $1,3,5,7,14,21,28,35,42,49$ post-injury. These tests were performed, in a blinded fashion, by a second investigator unaware of the treatment schedule.

\section{Histological preparation of spinal cord}

After termination of the treatment period (49th day postinjury), three animals in each group were selected for histology. These animals were sacrificed by intracardiac perfusion with $10 \%$ buffered formalin under deep level of pentobarbital anesthesia. Ten $\mathrm{mm}$ of spinal cord inclusive of the injured segment was removed and immersed in zinc buffered formaldehyde or phosphate buffered glutaraldehyde. Specimens were incised from side to side longitudinally, slightly above the level of the spinal roots. The dorsal half of the cord was embedded in paraffin, and four series of $5 \mu \mathrm{m}$-thick sections were made at $100 \mu \mathrm{m}$ intervals, beginning $100 \mu \mathrm{m}$ into the tissue. One section in each series was stained with HE, one with Luxol Fast Blue (LFB)-PAS stain for myelin and one with Sevier-Munger stain for axons, using standard histologic methods.

Sections were evaluated using four criteria on light microscopic examination. Three of the criteria were designed to assess the amount of tissue destruction. Malacia, if present, was scored as being $0-4$ in severity, according to the estimated proportion of the specimen's width affected in the most severely affected section. The amount of Wallerian degeneration was evaluated by assessing the degree of vacuolation and axonal degeneration distal to the central area of malacia. The amount of axonal loss proximal to the central focus of malacia was evaluated by examining Sevier-Munger stained tissues. The sum to these three scores, averaged over the four step-sections examined in each animal, was used to summarize the overall degree of histological tissue damage in the spinal cord specimens. The degree of reparative response was assessed by estimating the relative increase in the number of non-macrophage glial cells in the white matter proximal to the malacic lesion.

\section{Statistical analysis}

In this study we were primarily interested in comparing the groups at the end of the treatment time. The IP data were interval-scaled data and lent itself to a different analysis than the data on TSR and TS, which were ordinal. 
For the IP, a repeated measures analysis of variance was used. Repeated measures were being taken at the 42nd and 49th post-injury day and tested for group effects. Since there was some indication that there was more viability in the outcomes for the control group than the other groups, we also did some nonparametric comparisons for each time point. The Kruskal Wallis and Median tests were used. We also tested to see if the groups were comparable at baseline (preinjury). On the chance that the initial value might be related to the final inclined plane value, we used a relative measurement and defined RIP49 $=$ IP49/IPO. This value is essentially a percentage of the baseline value.

Since the TS were observed to range from two to five and since they were on an ordinal scale, a Kruskal Wallis test was used. For the TSR the Fisher's Exact test was used to compare the groups.

\section{Results}

Table 1 depicts the summary of the behavioral scores given to the control and the -treated animals before and after the compressive injury. The recovery curves for the IP and TS assigned to the groups are shown in Figures 1 and 2. Since 4-AP treatment was started at 21 days post-injury, the $2 \mathrm{mg} / \mathrm{kg}$ and the $4 \mathrm{mg} / \mathrm{kg} 4-\mathrm{AP}$ groups were actually given identical care up to 21 days. One would expect no difference in the groups up to 21 days. For the IP (Figure 1), the repeated measure analysis of variance taken at the 42nd and 49th day post-injury showed no significant difference across groups $(P=0.21)$. Since more variability in the outcome was seen for the control group, we performed nonparametric comparisons for each day using a Kruskal Wallis test. The results were consistent with the parametric analysis showing no significant group effect. Analysis of the TS (Figure 2) showed no significant treatment effect at 49th day post-injury $(P=0.26)$. The Fisher's Exact test on the TSR also showed no significant difference between groups $(P=1.0)$.

The microscopic appearance of the cord was similar between the control and the 4-AP-treated groups with considerable variation between individual animals. A majority of the rats had areas of malacia in the center of the spinal cord sampled that affected both the dorsal gray and white matter. The malacic cavities were irregular in shape, and differed in extent between the different step sections of a given specimen; in several cases there was rupture of the cavitation into the central canal of the cord. Malacic areas were characterized by irregular cavities (Figure 3), which were traversed by strands of connective tissue and small blood vessels. Foamy to granular macrophages, stained strongly with PAS, crowded the cavity lumens.

Distal to malacic foci, vacuolar change was usually the most widespread and swollen or fragmented axons occurred together with loss of myelin-staining and vacuolar change, suggesting they were areas of Wallerian degeneration. Sevier-Munger stains indicated almost no axonal preservation distal to the central part of the specimen in any of the spinal cords.

At proximal end of the specimen, there was variable preservation of axons, and additional vacuolar change was present (Figures 4 and 5). Numerous digestion vacuoles were present along swollen axon sheaths, and many of these LFB-positive macrophages were present. However, but segments of swollen and degenerating axons were also present (Figure 4).

Besides macrophages, numerous non-vacuolated polygonal glial cells were noted associated in degenerating white matter, both in the presence and absence of axons (Figure 4). While these cells could not be identified with certainty given the histochemical techniques used, their polygonal shape suggests they were probably Schwann cells, oligodendrocytes or astrocytes instead of macrophages.

Quantitative lesion scores for both degenerative changes and glial proliferation were extremely similar

Table 1 Comparison of the behavioral scores (incline plane, Toe spreading reflex, and Tarlov open field scores) in treated and control animals

\begin{tabular}{lcccc}
\hline & Control & $2 \mathrm{mg} / \mathrm{kg} 4-\mathrm{AP}$ & $4 \mathrm{mg} / \mathrm{kg} 4-\mathrm{AP}$ & Methylprednisolone \\
\hline Weight & $498 \pm 48$ & $460 \pm 48$ & $381 \pm 10$ & $420 \pm 30$ \\
IPB & $63.2 \pm 1.7$ & $64.1 \pm 1.3$ & $63.2 \pm 1.1$ & $62.5 \pm 2.0$ \\
IP1D & $34.1 \pm 10.7$ & $33.1 \pm 7.0$ & $37.0 \pm 11.2$ & $34.1 \pm 7.9$ \\
IP3D & $39.3 \pm 11.9$ & $37.5 \pm 11.0$ & $40.0 \pm 11.7$ & $40.7 \pm 10.7$ \\
IP49D & $57.2 \pm 5.4$ & $58.3 \pm 2.6$ & $60.6 \pm 1.8$ & $59.7 \pm 0.7$ \\
TSR1D & $1.1 \pm 0.8$ & $0.8 \pm 0.8$ & $0.5 \pm 0.7$ & $0.5 \pm 0.5$ \\
TSR3D & $1.3 \pm 0.7$ & $1.0 \pm 0.7$ & $0.8 \pm 0.8$ & $0.8 \pm 0.8$ \\
TSR49D & $1.8 \pm 0.3$ & $2.0 \pm 0.0$ & $2.0 \pm 0.0$ & $2.0 \pm 0.0$ \\
TS1D & $1.7 \pm 1.7$ & $1.1 \pm 1.8$ & $1.3 \pm 1.5$ & $1.2 \pm 1.4$ \\
TS3D & $2.1 \pm 1.8$ & $1.8 \pm 1.7$ & $2.0 \pm 1.6$ & $1.6 \pm 1.5$ \\
TS49D & $4.5 \pm 1.0$ & $5.0 \pm 0.0$ & $4.8 \pm 0.3$ & $5.0 \pm 0.0$ \\
\hline
\end{tabular}

4-AP = 4-aminopyridine-treated animals; IPB = Incline plane at baseline, 1st day (IP1D), 3rd day (IP3D) and 49 days (IP49D); $\mathrm{TSR}=$ Toe spreading reflex at 1st day (TSR1D), 3rd day (TSR3D) and 49 days (TSR49D); TS = Modified Tarlov's scale at 1st day (TS1D), 3rd day (TS3D) and 49 days (TS49D). Values are means \pm standard deviation 
between the two groups and there were no statistically significant differences between the groups in any of the individual or collective categories.

\section{Discussion}

Spinal cord injury is associated with variety of neuropathological changes which develop at an early or later stages of the injury. These events take place sequentially, with gray matter central hemorrhage as the primary finding. This event is followed by necrosis of the gray matter, and later in the surrounding white matter. In rats, changes affecting myelinated axons are seen approximately 4 days or later after the injury. However, distortion of myelin sheaths occurs as early as 1 to $4 \mathrm{~h}$ post-injury. ${ }^{21-22}$ Neural conduction is impaired by damage of the axon's myelin sheath. The injury leads to exposure of $\mathrm{K}^{+}$channels in the internodal region of the axon, ${ }^{1}$ and the afflux of $\mathrm{K}^{+}$ through the membrane blocks the conduction of action potentials.

4-AP, has all the characteristics of $\mathrm{K}^{+}$channel blockers. Blockade of $\mathrm{K}^{+}$channels is excitatory which results in prolongation of excitatory states in neurons and increasing neurotransmitter release and smooth muscle contraction. 4-AP has been shown to be effective in restoring loss of some sensory and motor functions in chronic but incomplete SCI models using a $1 \mathrm{mg} / \mathrm{kg}$ IV dose, which is within the limit of safety in animals. In chronic and incomplete injuries, 18$25 \mathrm{mg}$ IV of 4-AP has resulted in improvement in sensory scores, chronic pain and spasticity. ${ }^{12}$ However, only slight improvement has been observed in motor function. The initial 4-AP trial in SCI patients was through intravenous delivery of $2 \mathrm{mg}$ every $20 \mathrm{~min}$ up to $24 \mathrm{mg}$. This trial included six patients with chronic spinal cord injury: three with complete and three with incomplete lesions. ${ }^{1}$ The patients with complete paralysis did not benefit from 4-AP. The patients with incomplete injuries showed some evidence of improvement in neurological function. None of these patients had any side effects due to 4-AP administration. Nevertheless, 4-AP is a compound with toxic effects such as promoting neurotransmitter release and enhancement of neuronal excitability, inducing spontaneous synchronous activity which provokes seizures. $^{1,15}$ In fact, our experimental rats treated with $6 \mathrm{mg} / \mathrm{kg}$ of 4-AP developed generalized seizures immediately after the initial 4-AP administration.

In our study, we measured functional recovery of the chronically injured animals after daily administration of $4-\mathrm{AP}$ at $2 \mathrm{mg} / \mathrm{kg}$ and $4 \mathrm{mg} / \mathrm{kg}$ for period of 4 weeks. The neurological outcome was measured in each animal within $15 \mathrm{~min}$ after administration of 4-

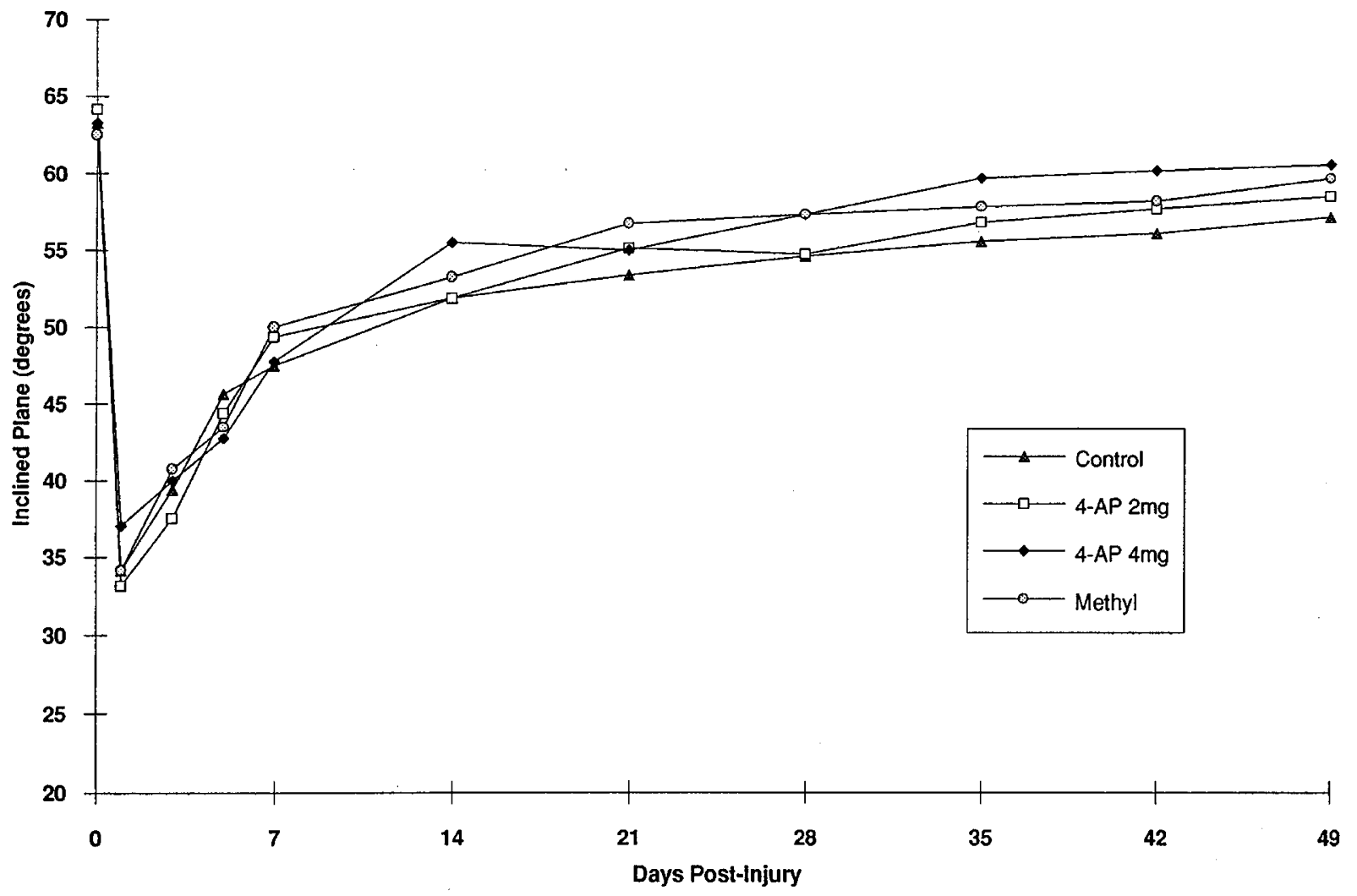

Figure 1 Treated $(2 \mathrm{mg} / \mathrm{kg}(n=8), 4 \mathrm{mg} / \mathrm{kg}(n=8)$, methylprednisolone $(n=8)$ and non-treated inclined plane (IP) scores. Recovery curves indicate the mean scores of each group at each time point tested (pre-injury scores at day 0 ). No statistically significant difference was observed at any time between the groups 
AP to ensure capturing possible transient improvements, as reported by others. ${ }^{15}$ The neurological scores obtained at day 49 post-injury was not significantly better than the non-treated control animals. This negative finding could be due to (a) lack of significant number of demyelinated axons which contribute to

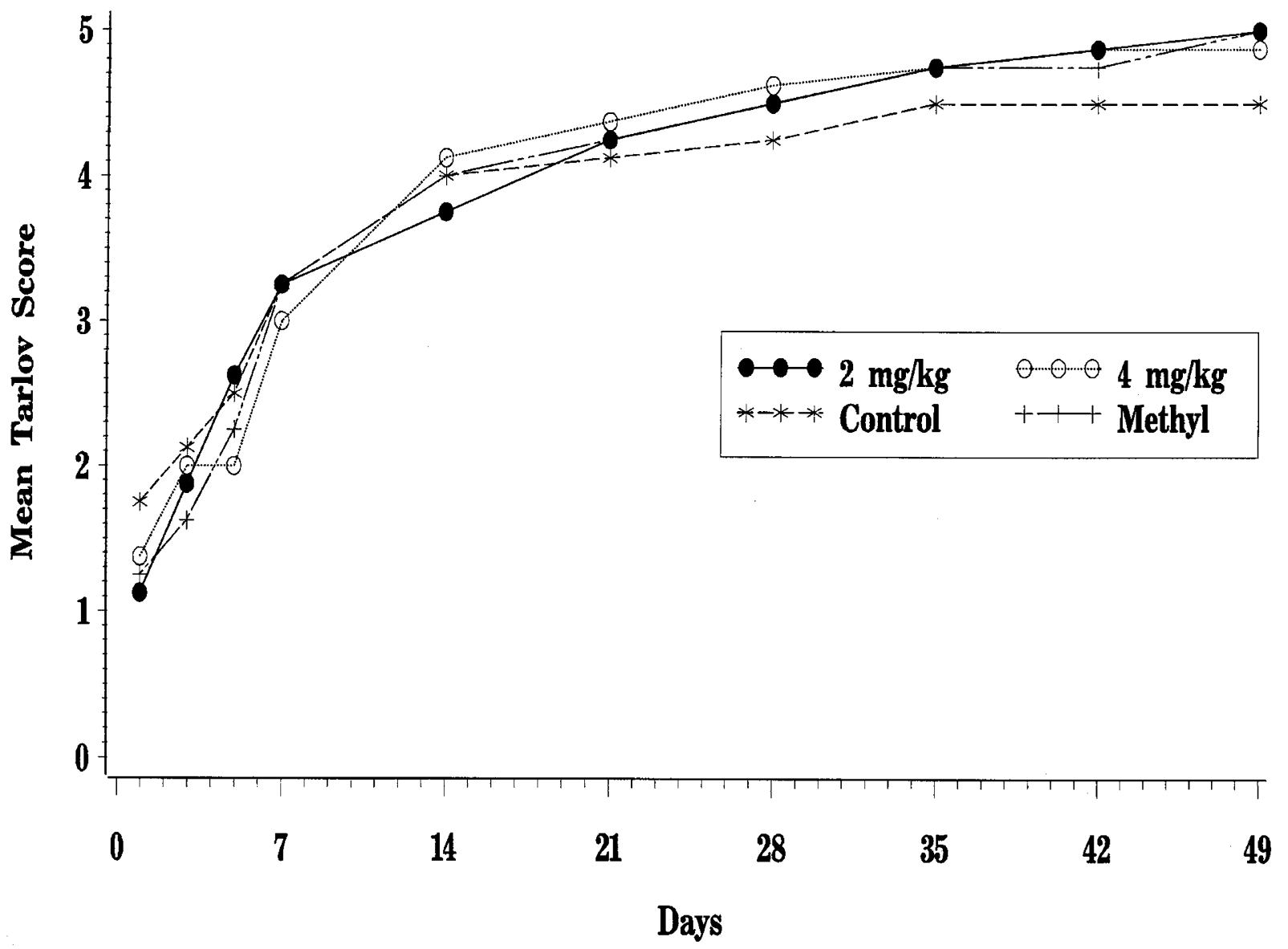

Figure 2 Treated $(2 \mathrm{mg} / \mathrm{kg}(n=8), 4 \mathrm{mg} / \mathrm{kg}(n=8)$, methylprednisolone $(n=8)$ and non-treated Tarlov scores (TS); open field walking scores. Recovery curves indicate the mean scores of each group at each time point tested (pre-injury scores at day 0 )

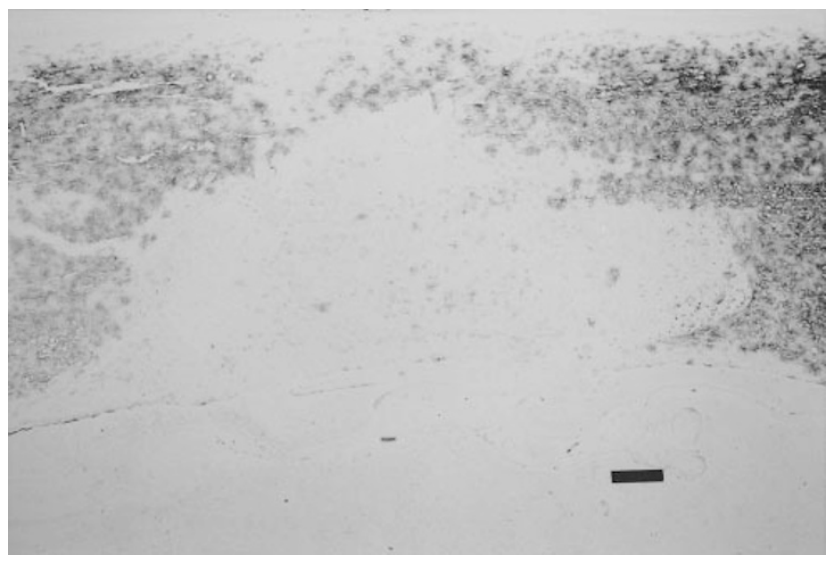

Figure 3 Longitudinally sectioned spinal cord from a 4aminopyridine treated rat, Sevier-Munger stain. Longitudinal sections of degenerating axons (black), frame a central malacic cavity, from which both axons and myelin are absent. $\mathrm{Bar}=200 \mu \mathrm{m}$

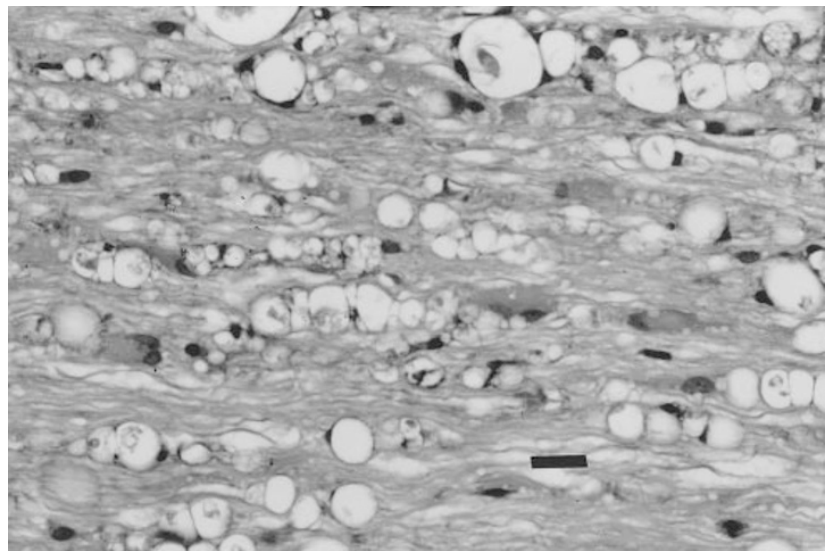

Figure 4 Higher magnification of a lesion proximal to an area of malacia demonstrates partial preservation of axons, as well as areas of axonal loss, Sevier-Munger stain. $\operatorname{Bar}=200 \mu \mathrm{m}$ 


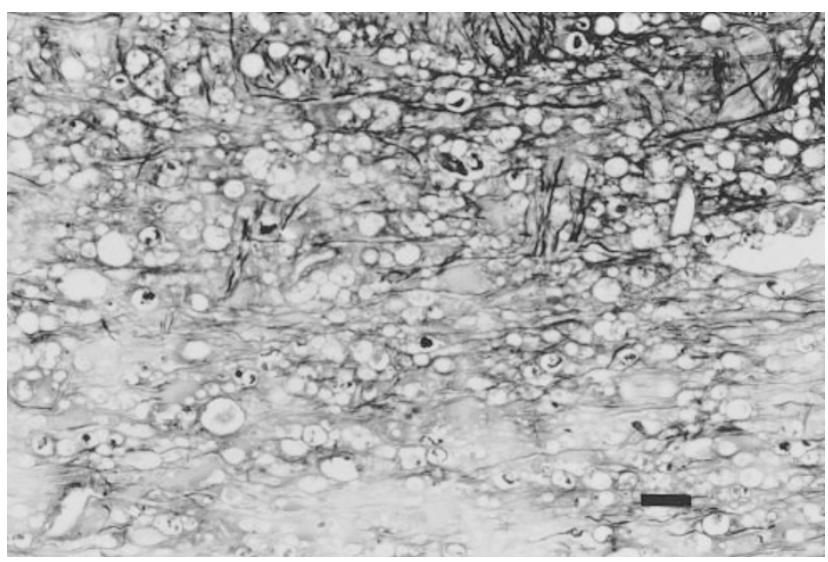

Figure 5 LFB/PAS stains of a similar area reveal longitudinal digestion chambers suggestive of axonal break down. Several remnants of axons remain visible. Increased numbers of polygonal glial cells are also present in this section. $\operatorname{Bar}=200 \mu \mathrm{m}$

functional outcome, (b) treatment dosage given was not adequate to provide sufficient 4-AP plasma concentration to contribute to a better functional outcome. The unresolved issues would still be the timing of the 4-AP treatment initiation, duration of the treatment, and 'optimum' treatment dosage. Further experimental studies are needed at higher injury levels, lower doses 4-AP doses $(0.5-1 \mathrm{mg} / \mathrm{kg})$, and different time windows for the treatment.

Large doses of methylprednisolone (MP) given shortly after SCI, significantly enhance recovery following the injury. ${ }^{23,24}$ This effect is probably achieved by the reduction of the lipid peroxidation, facilitation of impulse generation, or enhancement of spinal cord blood flow. ${ }^{25-27}$

The lipid peroxidation process plays a crucial role in the evolution of the secondary changes in the injured spinal cord. This fact has been linked to the postinjury microvascular damage and hypoperfusion, which lead to the secondary ischemic events in the tissue. $^{28}$ Therefore, the importance of prompt treatment (less than $8 \mathrm{~h}$ after trauma), has been recognized. ${ }^{23}$ In regard to the effect of steroid, several negative findings have been reported. ${ }^{27}$ High-dose of MP (1000 mg bolus and daily for 10 days) failed to improve recovery of motor or sensory function at 6 weeks and 6 months. ${ }^{23}$ However, if given within $8 \mathrm{~h}$ after injury, it significantly improved the neurologic recovery. ${ }^{23}$ In an experimental study to investigate the effect of MP on vascular injury associated with SCI, bolus injection of MP given at $30 \mathrm{mg} / \mathrm{kg}$ did not significantly affect the vascular injury index. ${ }^{29}$ Based on a similar model of injury, it was shown that while a single dose of $\mathrm{MP}$ at $30 \mathrm{mg} / \mathrm{kg}$ attenuated lactic acidosis in spinal tissue, the lactate levels rebounded to high levels soon after the elimination of the steroid. $^{30}$ Nevertheless, $30 \mathrm{mg} / \mathrm{kg}$ dosage given to contused cats, significantly improved recovery of evoked responses. ${ }^{31,27}$ Hall and his colleagues have reported the protective effect of $30 \mathrm{mg} / \mathrm{kg}$ MP in spinal cord ischemia resulting from spinal injury. ${ }^{24}$ In our study the single $30 \mathrm{mg} / \mathrm{kg}$ bolus injection of MP, given immediately after the injury, did not have any significant long-term beneficial effect in rats. The improvement in behavioral scores at 49 days postinjury was not any greater than those of control animals. Therefore, it appears that a single dosing is not ideal and supports a prolongation of dosing to maximize the chances of recovery.

Because of the small size of the specimens, the challenge of uniform tissue sampling, biological variations in the size and shape of the malacic cavity and in the location of the malacic segment within the spinal cord sample, it was not possible to examine exactly the same level of each lesion produced by mechanical trauma. However, portions of malacic cord were probably observed if they were present, because soft or cavitated tissue was apparent during preparation of the specimens. While the longitudinal orientation of the cord allowed fiber tracts transversing through the malacic areas be examined, the amount of adjacent tissue captured in the specimen probably varied according to the level and extent of malacia. These physical aspects of tissue handling probably reflected some of the variation observed in lesion scores.

Whenever malacia was present, downstream axonal degeneration produced Wallerian degeneration towards the cephalic end of the animal, in rough proportion to the size of the central malacic focus. Thus it is not appropriate to evaluate the amount of demyelination produced at these sites, because the majority of vacuolar change would be secondary to axonal loss. Axonal survival was evaluated on the opposite (caudal) side of the lesion, and significant axonal loss was still apparent in both treated and untreated animals. Such changes could reflect proximal dying back of axons secondary to the malacia or loss of axons after a primary demylelinating event. Whichever the cause, the lesions produced by compression in our rats appear more complex than those lesions induced by lysolecithin injection alone, ${ }^{32}$ in that axonal preservation within areas of myelin loss was less extensive. The presence of both primary and secondary demylelination in these areas also contributed to high lesion scores.

\section{References}

1 Hayes KC. 4-Aminopyridine for spinal cord injuries. Neurosci Forum 1993; 3: $1-6$

2 Blight AR. Effect of 4-Aminopyridine on axonal conductionblock in chronic spinal cord injury. Brain Res Bull 1989; 22: 47 52.

3 Blight AR, Gruner JA, Augmentation by 4-aminopyridine of vestibulospinal free fall responses in chronic spinal-injured cats. Journal of the Neurological Sciences 1983; 82: 145-159. 
4 Blight AR, Young W. Central axons in injured cat spinal cord recover electrophysiological function following remyelination by Schwann cells. J Neuro Sci 1989; 91: 15-34.

5 Blight AR. Axonal physiology of chronic spinal cord injury in the cat: Intracellular recording in Vitro. Neuroscience 1983; 10: $1471-1486$

6 Eidelberg E, Sullivan J, Brigham A. Immediate consequence of spinal cord injury: Possible role of potassium in axona conduction block. Surg Neurol 1985; 3: $317-321$.

7 Young $\mathrm{W}$ et al. Extracellular potassium activity and axonal conduction in spinal cord of myelin-deficient mutant rat. Exp Neurol 1989; 106: 41 - 51 .

8 Bever CT et al. Preliminary trial of 3,4-Diaminopyridine in patients with multiple sclerosis. Ann Neurol 1990; 27: 421-427.

9 Davis FA, Stefoski D, Rush J. Orally administered 4Aminopyridine improves clinical signs in multiple sclerosis. Ann Neurol 1990; 27: 186-192.

10 Diemen Van HAM, Dongen Van TMMM, Dammers JWHH, Polman $\mathrm{CH}$. Increased visual impairment after exercise (Uhthoff's phenomenon) in multiple sclerosis: Therapeutic possibilities. Eur Neurol 1992; 32: $231-234$.

11 Stefoski DD et al. 4-Aminopyridine in multiple sclerosis Prolonged administration. Neurology 1991; 41: 1344-1348.

12 Hansebout RR, Blight AR, Fawcett S, Reddy K. 4-Aminopyridine in chronic spinal cord injury: A controlled, double-blind, crossover study in eight patients. $J$ Neurotrauma $1993 ; 10$ : $1-18$.

13 Hayes KC et al. Preclinical trials of 4-Aminopyridine in patients with chronic spinal cord injury. Paraplegia 1993; 31: 216-224.

14 Waxman SG. Aminopyridine and the treatment of spinal cord injury. J Neurotrauma 1993; 10: $19-24$.

15 Blight AR, Toombs JP, Bauer MS, Widmer WR. The effets of 4 Aminopyridine on neurological deficits in chronic cases of traumatic spinal cord injury in dogs: A phase I clinical trial. $J$ Neurotrauma 1991; 8: $103-119$.

16 Pratt K, Toobs JP, Widmer WR, Borgemens RB. Plasma and cerebro-spinal fluid concentrations of 4-aminopyridine following intravenous injection and metered intrathecal delivery in canines. J Neurotrauma 1995; 12: 23 - 29

17 Haghighi SS, Hall ED, Geng XZ, Johnson GC. Therapeutic value of 21-aminosteroid U74389F in acute spinal cord injury. Neurological Res 1993; 15: $321-326$.

18 Rivlin AS, Tator CH. Objective clinical assessment of motor function after experimental spinal cord injury in the rat. $J$ Neurosurg 1977; 47: $577-581$
19 Gale K, Kerasidis H, Wrathall JD. Spinal cord contusion in the rat: behavioral analysis of functional neurologic impairment. Exp Neurol 1985; 88: $123-134$.

20 Tarlov IM. Spinal cord compression studies III. Time limits for recovery after gradual compression in dogs. Arch Neurol Psychiat 1954; 7: $588-597$.

21 Holtz A, Nystrom B, Gerdin B, Olsson Y. Neuropathological changes and neurological function after spinal cord compression in the rat. $J$ Neurotrauma 1990; 7: 155-167.

22 Wagner FC, Dohramann GJ. Alterations in nerve cells and myelinated fibers in spinal cord injury. Surg Neurol 1975; 3: $125-$ 131

23 Braken MB et al. Methylprednisolone or naloxone treatment after acute spinal cord injury: 1-year follow-up data: results of the Second National Acute Spinal Cord Injury Study. $J$ Neurosurg 1992; 76: 23-31.

24 Hall ED, Wolf DL, Braughler JM. Effect of a single large dose of methylprednisolone sodium succinate on experimental posttraumatic spinal cord ischemia. Dose-response and time-action analysis. $J$ Neurosurg 1984; 61: $124-130$.

25 Anderson DK. Chemical and cellular mediators in spinal cord injury. J Neurotrauma 1992; 9: 143 - 145 .

26 Hall ED, Braughler JM. Glucocorticoid mechanisms in acute spinal cord injury: a review and therapeutic rationale. Surg Neurol 1982; 8: $320-327$.

27 Young W, Flamm ES. Effect of high-dose corticosteroid therapy in blood flow, evoked potentials, and extracellular calcium in experimental spinal cord injury. J Neurosurg 1982; 57: 667-673.

28 McCall JM, Braughler JM, Hall ED. Lipid peroxidation and the role of the oxygen radicals in CNS injury. Act Anesth Belg 1987; 38: $373-379$

29 J.Xu ZXQ, Hoggan EL, Perot PL. Protective effect of methylprednisolone on vascular injury in rat spinal cord injury. $J$ Neurotrauma 1992; 9: 245 - 253.

30 Braughler JM, Hall ED. Effects of multi-dose methylprednisolone sodium succinate administration on injured cat spinal cord neurofilament degradation and energy metabolism. $J$ Neurosurg 1984; 61: $290-295$

31 Ley GDE, Leybaert L. Effect of flunarzine and methylprednisolone on functional recovery after experimental spinal injury. $J$ Neurotrauma 1993; 10: 25 - 35 .

32 Yezierski RP, Devon RM, Videdomini JP, Broton JG. Effects of dorsal column demyelination on evoked potentials in nucleus gracilis. J Neurotrauma 1992; 9: $231-241$. 